\title{
Papel e utilização das TDIC no contexto da Educação Básica Brasileira
}

\section{Role and use of TDIC in the context of Brazilian basic education}

\author{
Liamara Scortegagna, Carla de Lima \\ Universidade Federal de Juiz de Fora - UFJF
}

\begin{abstract}
Resumo
Este artigo apresenta uma pesquisa desenvolvida através do Programa de Extensão Universitária “eTEIA: Tecnologias de informação e comunicação na Educação: Inovação na sala de Aula" da Universidade Federal de Juiz de Fora (UFJF) com o objetivo de conhecer a realidade do uso das TDIC na sala de aula, capacitar e informar os professores da rede pública no uso das tecnologias na sala de aula e ainda, melhorar a formação dos alunos bolsistas do programa de extensão através de uma proposta integrada de ensino, pesquisa e extensão. Os resultados apresentados nos mostram que a utilização das TDIC na sala de aula nas escolas pesquisadas ainda é precária, porém os professores tem consciência de que as tecnologias facilitam o processo de ensino e aprendizagem e que, se sentem mais seguros após a participação de algum tipo de capacitação. Com isso, é possível concluir que é necessária qualificação e formação continuada e permanente sobre o uso das tecnologias no processo educacional, munindo os professores pesquisados de conhecimentos técnicos e pedagógicos oferecendo a estes condições para entenderem como integrar o uso das TDIC em suas práticas em sala de aula.

Palavras-chave: TDIC; Formação de professores; Programa e-TEIA.
\end{abstract}

\footnotetext{
Abstract

This article presents a research developed t This article presents a research developed through the University Extension Program "e-TEIA: Information and Communication Technologies in Education: Innovation in the Classroom" of the Federal University of Juiz de Fora (UFJF) in order to know the reality of the use the TDIC in the classroom, to train and inform the teachers of the public network in the use of the technologies in the classroom and also to improve the training of scholarship students in the extension program through an integrated teaching, research and extension proposal. The results show that the use of TDIC in the classroom in the schools studied is still precarious, but teachers are aware that technologies facilitate the teaching and learning process and they feel more secure after participating of some kind of capacity building. Therefore, it is possible to conclude that a continuous qualification and ongoing training on the use of technologies in the educational process is necessary, providing the researched teachers with technical and pedagogical knowledge, offering these conditions to
}

understand how to integrate the use of TDIC in their classroom practices.

Keywords: TDIC; Teacher training; e-TEIA Program.

\section{Introdução}

As tecnologias digitais de informação e comunicação (TDIC) vêm provocando inúmeras mudanças no cotidiano das pessoas, criando diferentes modos de vida, de pensamento e de percepção. Na educação, têm transformado a concepção de ensinar e de aprender, exigindo redimensionamento desses processos.

O imenso potencial destas tecnologias sobre o ensino e a aprendizagem pode trazer muitas contribuições tanto para os alunos quanto para os professores. Os recursos estimulam os alunos a desenvolverem habilidades intelectuais de pesquisa e investigação, pois o conteúdo não lhes é dado pronto. Isso os instiga a estarem mais concentrados $\mathrm{e}$ interessados em aprender, estimulam a buscar informações sobre um assunto e relacioná-las com aquelas adquiridas em outros momentos e, ainda, promovem cooperação entre os alunos.

Para o professor, as tecnologias auxiliam na obtenção rápida de informação sobre recursos instrucionais, interação com os alunos diferente daquela ocorrida nas aulas tradicionais. A utilização destas ferramentas permite que sejam criadas situações de aprendizagens ricas, complexas, diversificadas, não fazendo com que todo o trabalho fique sobre o professor.

Para que possamos munir os professores de conhecimentos e ferramentas, objetivando a criação de novas situações de aprendizagens, necessariamente é imprescindível a capacitação continuada, pois nem sempre estes receberam formação específica no uso das TDIC durante o curso de graduação.

Este artigo tem como objetivo mostrar a realidade de escolas de munícipios do Estado de Minas Gerais (MG) - Brasil, quanto ao uso das TDIC na sala de aula, bem como apresentar dados da formação e capacitação dos professores destas, no uso das tecnologias no processo de ensino e aprendizagem.

A pesquisa foi desenvolvida a partir da execução de um programa de extensão da Universidade Federal de 
Juiz de Fora - UFJF, denominado "Tecnologias de informação e comunicação na Educação: Inovação na sala de Aula - e-TEIA", onde envolveu os alunos do curso de Licenciatura em Computação da UFJF e o público alvo da pesquisa, foram os professores das escolas públicas de três munícios do Estado de MG.

Para apresentação dos dados e análise dos resultados, o artigo está estruturado da seguinte forma: inicia-se com uma apresentação do tema, objetivos e justificativa. Buscamos em alguns autores o embasamento teórico sobre a formação do professor para a utilização das TDIC na sala de aula, apresentamos o programa de extensão e-TEIA e sua ligação com o contexto da pesquisa e finalizamos apresentado os dados com as devidas análises e as considerações finais.

\section{Formação do professor para a utilização das TDIC na sala de aula}

Desde o início da década de 90 alguns governos vêm investindo continuamente no aparelhamento das escolas públicas com a implantação de laboratórios de informática e mais recentemente, com o acesso à Internet. No mesmo período, as escolas particulares também começaram a investir pesadamente na montagem dessas salas e em equipamentos de multimídia, como computadores, datashow, telões e acesso à internet.

Dados do uso das TDIC na escolas brasileiras no ano de 2015 publicados em 2016 CETIC.BR [CETIC, 2016], relatam que $93 \%$ das escolas públicas de áreas urbanas possuíam algum acesso à Internet, enquanto a conexão a rede está universalizada nas escolas privadas. Na sala de aula, no entanto, o acesso à Internet estava disponível em $43 \%$ das públicas e em $72 \%$ das privadas. Com relação ao uso do computador e da Internet para ações pedagógicas, a pesquisa mostra que $73 \%$ dos professores o fizeram em ao menos uma das atividades com os alunos que são investigadas pela pesquisa (resultado que foi de $70 \%$ entre professores das escolas públicas e $84 \%$ das escolas privadas)

$\mathrm{Na}$ mesma pesquisa, quando buscamos dados sobre a formação dos professores, constata-se que 39\% dos professores que responderam a pesquisa afirmara ter cursado uma disciplina específica na graduação sobre o uso de TDIC em atividades pedagógicas, sendo que, entre os entrevistados com idade inferior a 30 anos, esse número foi de 54\%. Para além dos programas institucionais, 91\% dos professores disseram aprender sozinhos a utilizar o computador e internet ou a se atualizarem sobre eles.

Apesar dos dados positivos quanto ao percentual de escolas com infraestrutura de TDIC e acesso à internet e, de professores que utilizam as TDIC para ações pedagógicas, ainda observamos um resultado negativo quanto a utilização destas na sala de aula.

O motivo se reporta de que a implantação da infraestrutura das tecnologias se baseou somente no pressuposto de que faltava apenas o computador e a internet para que o processo de modernização das escolas e do ensino se desse de forma natural, como se isso fosse um processo simples e automático e isso, pode ser observado na pesquisa CETIC.BR [CETIC, 2016] que, aponta um percentual de apenas $39 \%$ de professores que tiveram alguma formação específica durante a graduação para a utilização das TDIC na sala de aula, aumentando o índice para os que possuem idade inferior a 30 anos.

Paralelamente a falta formação especifica para a atuação com TDIC na sala de aula, vimos uma generalizada falta de vontade ou desconhecimento por parte dos professores que resistem ao uso das tecnologias.

Sob argumentos que vão do "não preciso disso" até o "não sei como usar", são poucos os professores que se dispõem a aprender a usar as TDIC de forma pedagógica ou mesmo a repensar suas práticas pedagógicas diante da necessidade de inserir seus alunos no universo digital onde eles e o próprio professor, já vivem há muito tempo.

Após duas décadas da inserção das tecnologias na escola, já não faz mais nenhum sentido discutir se vale ou não a pena usar os computadores, a internet e as TDIC de forma geral.

$\mathrm{O}$ mundo, independentemente de preconceitos ou vontades de alguns professores e da má vontade da maioria dos gestores, já definiu que não poderá continuar existindo sem essas tecnologias. É simplesmente impossível conceber um mundo e uma escola sem as tecnologias, a menos que se faça a opção por uma vida eremita.

Nesse contexto, o uso das TDIC na sala de aula deixa de ser uma possibilidade a mais e passa a ser uma necessidade que se impõe tão fortemente quanto a necessidade da lousa e do giz, que ainda existirão por um bom tempo. Mas, como promover esse uso?

Primeiro, são necessárias condições físicas e tecnológicas nas escolas, como, laboratórios de informática e acesso à internet. Segundo, necessitamos de professores dispostos a cumprir seu papel de educador e não apenas o seu compromisso de "dador de aulas", e, finalmente, é necessário que os professores sejam formados e capacitados para o uso das TDIC.

\section{Formação do professor}

O uso das TDIC na educação enfatiza o fato de o professor de uma disciplina curricular ter conhecimento dos potenciais educacionais das tecnologias, além de ser capaz de alternar, adequadamente, atividades não informatizadas de ensino e aprendizagem e atividades que usam tecnologias.

Para ser capaz de integrar as tecnologias nas atividades pedagógicas, a formação do professor necessita atingir quatro pontos fundamentais, conforme afirma Scortegagna (2014):

1) Propiciar ao professor condições para entender as tecnologias como uma nova maneira de representar o conhecimento, provocando um redimensionamento dos conceitos já conhecidos e 
possibilitando a busca e compreensão de novas ideias e valores;

2) Usar as tecnologias com esta finalidade requer a análise cuidadosa do que significa ensinar e aprender, bem como demanda rever o papel do professor neste novo contexto; Propiciar ao professor a vivência de uma experiência que contextualiza o conhecimento que ele constrói.

3) É o contexto da escola e a prática dos professores que determinam o que deve ser abordado nas atividades de formação; Prover condições para o professor construir conhecimento sobre as técnicas computacionais, entender por que e como integrar o computador em sua prática pedagógica e ser capaz de superar barreiras de ordem administrativa e pedagógica.

4) A integração do conhecimento computacional, da prática pedagógica e das especificidades institucionais possibilita a transição de um sistema fragmentado de ensino para uma abordagem integradora de conteúdo voltada para a resolução de problemas específicos do interesse de cada aluno; Criar condições para que o professor saiba recontextualizar o que foi aprendido e a experiência vivida durante a formação para a sua realidade de sala de aula, compatibilizando as necessidades de seus alunos e os objetivos pedagógicos que se dispõe a atingir. Sem esta recontextualização, o professor tende a impor no seu contexto de trabalho um conhecimento que foi adquirido em uma situação diferente da sua realidade.

Assim, significa que esta formação não pode se restringir à passagem de informações sobre o uso pedagógico das TDIC. Deve-se oferecer condições para o professor construir conhecimento sobre técnicas computacionais e entender por que e como integrar o computador em sua prática pedagógica.

Além disso, essa formação deve acontecer no local de trabalho e utilizar a própria prática do professor como objeto de reflexão e de aprimoramento, servindo de contexto para a construção de novos conhecimentos.

\section{Mudança de postura/ação do professor}

O trabalho do professor é fundamental nos projetos de inovações tecnológicas, até porque "a qualidade educativa destes meios de ensino depende, mais do que de suas características técnicas, do uso ou exploração didática que realiza o docente e do contexto em que se desenvolve" (LIGOURI, 1997).

Para Valente (1993), o professor deixa de ser o repassador do conhecimento para ser o criador de ambientes de aprendizagem e facilitador do processo pelo qual o aluno adquire conhecimento.

Demo (1998), tentando redefinir o papel do professor, apresenta-o como o orientador do processo reconstrutivo do aluno, através da avaliação permanente, do suporte em termos de materiais a serem trabalhados, da motivação constante e da organização sistemática do processo.
Moran (1998) considera que o ensino com as novas mídias deveria questionar as relações convencionais entre professores e alunos. Para tanto, define o perfil desse novo professor como: ser aberto, humano, valorizar a busca, o estímulo, o apoio e ser capaz de estabelecer formas democráticas de pesquisa e comunicação.

De modo geral, os professores necessitam mudar sua postura/ação propondo aos seus alunos desafios compatíveis com a sua realidade, além de propor outros que eles possam selecionar, descrever, executar, depurar, analisar os resultados e refletir individualmente ou coletivamente, com ou sem a ajuda do professor.

Assim, segundo Scortegagna (2014), é necessário que o professor:

- Crie um ambiente de confiança, respeite as diferenças sociais e econômicas existentes em um grupo heterogêneo de uma sala de aula. Esse grau de confiança pode ser estendido com a criação do que podemos chamar de "contrato de trabalho" ou "acordo". Nele são estabelecidas algumas "regras" para o bom desenvolvimento dos trabalhos e das relações entre ambos: distribuição de responsabilidades, determinação de prazos, permissão ou proibição de determinados recursos, ações, entre outras;

- Seja o consultor, o articulador, o orientador, o especialista e o facilitador do processo de desenvolvimento realizado pelo aluno;

- Além da humildade, não deve ter inibições em reconhecer seus próprios conflitos, erros e limitações em relação ao conhecimento, pois não é detentor de todo o "saber". Nessas limitações, estão inclusos também os aspectos tecnológicos (manuseio operacional das tecnologias);

- Saia da sua "zona de conforto" e mostrar para o seu aluno que além de ensinar ele também pode aprender e o aluno, por sua vez, perceberá que além de aprender também poderá ensinar;

- Respeite os diferentes estilos e ritmos de aprendizagem dos alunos;

- Desafie o aluno em um nível de pensamento superior ao trabalhado, para que ele possa pesquisar e se aprofundar cada vez mais nos diversos temas;

- Estimule o aluno a aprender sempre, desenvolvendo assim suas próprias estratégias de aprendizagem, seus métodos, suas técnicas, enfim, sua autonomia intelectual.

Essa nova postura/ação docente provocará outras mudanças, especificamente na forma de ensinar e de aprender.

$\mathrm{Na}$ forma de ensinar, a sequência dos conteúdos deixa de ser linear e passa a ser flexível; os exercícios deixam de ser "modelos prontos" para terem uma análise mais global da realidade; o conteúdo não mais gerará o problema e sim o problema irá gerar o conteúdo dentro de um contexto estabelecido, e as fontes de consultas passam a ser infinitas: livros, apostilas, revistas, cinema, museu, internet entre 
outras, e consultadas, não somente na escola, mas principalmente fora dela.

$\mathrm{Na}$ forma de aprender, o aluno passa a ser um personagem ativo, questionador, conhecedor de seus direitos e também de seus deveres. Participa ativamente do processo de construção de sua própria aprendizagem e desenvolvimento e, ainda, através da autonomia intelectual adquirida, verifica que pode também aprender sozinho, mas que o grande potencial é aprender de maneira colaborativa.

\section{O programa e-TEIA}

O programa de extensão e-TEIA foi planejado com o objetivo de ampliar a formação dos alunos do curso de Licenciatura em Computação, inserindo-os no cotidiano de escolas da rede pública com o intuito de capacitar e informar os professores e futuros professores no uso das TDIC na sala de aula contribuindo assim, para a melhoria do processo de ensino e aprendizagem nas escolas das cidades/polos da UFJF, bem como melhorar a formação dos alunos do curso, através de uma proposta integrada de ensino, pesquisa e extensão e ainda, aproximar os alunos da modalidade à distância com a Instituição, promovendo a construção de um processo de identidade e pertencimento.

O curso de Licenciatura em Computação é um dos sete cursos de graduação ofertados na modalidade EAD pela UFJF, através do Programa Universidade Aberta do Brasil - UAB, atuando em 13 polos de apoio presencial/cidades no Estado de Minas Gerais e possui 363 alunos matriculados.

\section{Apresentação e análises dos dados}

A primeira edição do programa e-TEIA, ocorreu no período de novembro de 2015 à maio de 2017 e os alunos bolsistas selecionados pertenciam aos polos UAB/UFJF da cidade de Juiz de Fora, Ubá e Timóteo.

Como a maioria dos alunos não residiam na cidade sede da UFJF, todas as reuniões, orientações e atividades foram desenvolvidas à distância com a mediação, interação e comunicação através do Ambiente Virtual Moodle. Destaca-se que o Moodle é o AVA utilizado para o processo de ensino e aprendizagem na UFJF para a modalidade EAD e os alunos já são habituados com o espaço virtual. Por este motivo, foi criado um AVA exclusivo para o programa onde constam todas as informações, documentos e comunicações do programa.

\section{Fase 1: Seleção das escolas, desenvolvimento e aplicação de pesquisa de campo inicial}

$\mathrm{Na}$ primeira fase do programa os bolsistas, a partir da orientação dos professores, buscaram e definiram o objetivo da pesquisa e desenvolveram um questionário para apurar a realidade quanto ao uso de TIC na sala de aula, bem como a definição da população a ser pesquisada.

Cada bolsistas selecionou de duas a três escolas em suas cidades, e, no período de novembro de 2015 a maio de 2016, foram aplicados 121 questionários em 9 escolas da rede pública de ensino sendo seis escolas municipais e três estaduais.

$\mathrm{O}$ questionário foi desenvolvido a partir de cinco grupos de questões com os seguintes temas: Grupo 1: Informações sobre a formação geral e específica dos professores; Grupo 2: Utilização das TIC em sala de aula; Grupo 3: Dificuldades em usar as TIC em sala de aula e os motivos da não utilização; Grupo 4: Opinião sobre o uso das TIC no processo de ensino e aprendizagem: e ainda, no Grupo 5: Interesse do professor em participar de palestras e oficias sobre o uso das TIC na educação.

A partir das respostas dos questionários observamos que dos 121 professores participantes, $29,8 \%$ possuem somente graduação, $60,3 \%$ possuem especialização lato sensu, $8,3 \%$ mestrado e $1,7 \%$ doutorado.

$\mathrm{O}$ resultado mostra que é alto o índice de professores da rede pública pesquisada que ainda possuem somente o curso de graduação e, com isso, observa-se a necessidade de formação continuada e permanente.

Quando do questionamento sobre a formação específica para o uso das TIC na educação foram solicitadas três informações: (a) Se os professores cursaram disciplinas voltadas para a utilização das TIC na educação durante sua formação (graduação); (b) Se os professores fizeram algum curso específico para a utilização das TIC na educação e, (c) Se apenas utilizaram recursos tecnológicos como alunos de algum curso de formação ou aperfeiçoamento. Assim obtivemos o seguinte resultado: $44,6 \%$ cursaram alguma disciplina na graduação que auxiliou na utilização das TIC na educação, 32,2\% fizeram cursos específicos para a utilização das TIC e 48,7\% apenas utilizaram algum recurso tecnológico como aluno de algum curso de formação ou de aperfeiçoamento.

Apesar dos professores responderem que já tiveram algum contato com as TIC na sua formação inicial, o índice de professores que fizeram algum tipo de curso específico para o uso das TIC em sala de aula aparece como menor e isso reforça a necessidade de formação continuada, especificamente em tecnologias na educação, pois todos os processos e tecnologias evoluem de forma muito rápida.

Porém, a formação continuada e específica para utilização das tecnologias na sala de aula deve ser analisada sob dois aspectos a saber, a formação técnica e a formação pedagógica, pois somente desta forma é que podemos obter resultados concretos.

No Grupo 2 das questões solicitamos aos professores informações sobre a utilização de TIC no processo educacional, principalmente a utilização dos laboratórios de informáticas das escolas. Deste grupo, obtivemos que $62,8 \%$ nunca utilizam o laboratório de informática da escola com seus alunos, 17,4\% usam semanalmente, $6,6 \%$ uma vez por mês e $13,2 \%$ não responderam as questões.

$\mathrm{Na}$ sequência (Grupo 3), questionamos se os professores tinham dificuldades em utilizar as TIC no processo educacional na escola e ainda sobre quais 
eram os motivos da não utilização destas. Para este grupo de questões obtivemos um índice de 59,5\% de respostas positivas, ou seja, que possuem dificuldades em utilizar os recursos tecnológicos disponíveis, $38,8 \%$ não possuem dificuldade, e, $1,7 \%$ não responderam as questões. Aprofundando os questionamentos, buscamos conhecer quais os motivos da não utilização de tais recursos, pois apenas apontar que existem dificuldades não era o suficiente para que pudéssemos dar qualquer tipo de encaminhamento pós pesquisa. Neste grupo de questões os professores poderiam pontar mais de um motivo elencado pelos pesquisadores. Assim, 50,4\% assinalaram que "Turmas grandes dificultam o acesso e o uso dos poucos recurso tecnológicos que a escola oferece"; $34,7 \%$ alegam "serem inseguros e com falta de prática na utilização das TIC"; 29,7\% apontam que é "necessário cumprir com um planejamento de conteúdo muito grande e que não sobra tempo para utilizar as TIC"; 28,1\% apontam a "falta de suporte técnico nos laboratórios" como motivo para não utilização; 26,4\%, alegam que "os alunos são indisciplinados" e que isso é um impeditivo para a utilização dos recursos tecnológicos; e, ainda, 9,9\% apontou a "falta de incentivo da direção da escola" como motivo.

A maioria dos professores pesquisados apontam que possuem dificuldades para utilizar os recursos tecnológicos na sala de aula e os motivos são diversos. Sabemos que na realidade de muitas escolas, seja em relação a estrutura física/tecnológica, bem como no número de alunos em sala de aula, como apontados pelos pesquisados, podem aumentar as dificuldades na utilização das TIC no processo educacional, porém com as novas tecnologias existentes, é possível amenizar tais situações. Um exemplo é o BYOD ou Bring Your Own Device (traga seu próprio dispositivo), também conhecido como BYOT ou Bring Your Own Technology (traga sua própria tecnologia) que, refere-se à prática dos alunos trazerem seus próprios laptops, tablets, smartphones ou outros dispositivos móveis com eles para a escola.

Porém, os professores apontaram que se sentem inseguros com a falta de prática na utilização das TIC e esta situação só é possível superar com formação continuada e prática no dia a dia.

No Grupo 4 de questões, nosso interesse foi saber qual a opinião dos professores sobre se as "TIC facilitam ou não o processo de ensino e aprendizagem". Das respostas, 79,3\% afirmam que o uso das TIC facilitam o processo de ensino e aprendizagem, $10,7 \%$ são contrários, apontando que não facilitam, 7,4\% disseram que somente "as vezes facilitam" e 2,5\% não responderam as questões.

Os dados apresentados relatam que os pesquisados, apesar de terem dificuldades com o uso das TIC em sala de aula, possuem consciência, na sua maioria, que as TIC facilitam o processo de ensino e aprendizagem. Essa declaração é defendida por autores como Moran
(2000), Kenski (2008), Masetto (2000), Demo (2009), entre outros.

Para finalizarmos a pesquisa da primeira fase do programa e-TEIA, solicitamos aos professores se estes tinham interesse em participar de palestras sobre o uso das TIC na sala de aula ofertadas pelo grupo de bolsistas. Das respostas, obtivemos $85,9 \%$ como positivas, $10,7 \%$ como não tem interesse e $3,3 \%$ não responderam as questões.

Com a Fase 1 do programa e-TEIA finalizado e os dados analisados, o grupo do programa e-TEIA passou a executar as Fases 2 e 3 conjuntamente.

Fase 2 e 3: Definição e cronograma das palestras e pesquisa sobre os temas

Na Fase 2, que compreendeu no período de junho a agosto de 2016, a equipe de bolsistas juntamente com os professores da UFJF, iniciam a definição do cronograma das palestras, bem como os temas e a metodologia a serem trabalhados. Após a escolha, inicia-se a pesquisa bibliográfica, encerando-se assim também a Fase 3 do programa.

A partir da análise do questionário inicial, foram definidos os seguintes temas para as palestras, sendo, "Redes sociais na educação", "Uso pedagógico de mídias na escola" e "Games educacionais". E, o cronograma de execução proposto para setembro a dezembro de 2016.

\section{Fase 4: Desenvolvimento/aplicação das palestras}

Nesta fase, os bolsistas retornaram às escolas escolhidas, conversaram com os diretores e agendaram horários para o desenvolvimento das palestras com os professores da rede pública que responderam o questionário inicial e demostraram interesse em participar das palestras.

$\mathrm{O}$ número de participantes nas palestras correspondeu ao número de respostas ao questionário inicial (121), apresentando uma pequena variação para mais, totalizando em 388 ouvintes nos três temas ofertados. As palestras ocorreram no período de setembro a dezembro de 2016.

\section{Fase 5: Aplicação da pesquisa de campo final}

A Fase 5, foi destinada a elaboração e aplicação de uma pesquisa aos participantes após as palestras terem sido ministradas. $\mathrm{O}$ questionário apresentou 8 questões, dividida em três grupos, sendo Grupo $1 \mathrm{com}$ o objetivo de avaliar as palestras, quanto ao tema, qualidade do conteúdo e o conhecimento do aluno/bolsista do e-TEIA. Grupo 2 saber se o ouvinte/professor possuía conhecimento no tema abordado, bem como se sentiu alguma dificuldade nos conteúdos que foram apresentados.

Buscou ainda através do Grupo 3 de questões, saber se o ouvinte/professor após as palestras, se sentiu mais seguro para utilizar o laboratório de informática ou outros recursos tecnológicos no processo de ensino e aprendizagem e, se utilizaria algum dos recursos tecnológico apresentados durante as palestras. 
Foram encaminhados os questionários no período de dezembro de 2016 a fevereiro de 2017 e, obtivemos 113 respostas. Ressalta-se que o professor/ouvinte que participou das três palestras, respondeu apenas um questionário. Sendo assim, o número de respostas obtidos foi considerável muito bom para a análise dos resultados finais.

\section{Fase 6: Análise das respostas}

$\mathrm{O}$ primeiro grupo de questões referiu-se à avaliação do aluno/bolsista, a qualidade das palestras e conteúdos. Foi solicitado que o professor/ouvinte classificasse a(s) palestra(s) em "ótima", "boa" ou "razoável". Dos respondentes, 76\% consideraram "ótima", 23\% "boa" e apenas 1\% declarou que foram "razoável". $\mathrm{Na}$ sequência, questionamos se o palestrante (aluno/bolsista) foi claro na apresentação da palestra e, todos os respondentes afirmaram de forma positiva que sim. E ainda, em relação à qualidade dos conteúdos apresentados, 95\% dos professores/ouvintes afirmaram ser "ótima" e apenas $5 \%$ considerou "razoável". Percebe-se no resultado deste grupo de questões, a consequência da preparação do aluno/bolsista para a realização das palestras, bem como o efeito positivo da formação do curso de licenciatura na atuação destes.

No Grupo 2 de questões, objetivou-se saber sobre o conhecimento e dificuldades do professor/ouvinte com os temas abordados. Ao questionar se conhecia o(s) tema(s) abordado(s), $24 \%$ não possuía nenhum tipo de conhecimento, 29\% pouco, outros $29 \%$ com conhecimento médio e apenas $18 \%$, possuía conhecimento pleno sobre o tema abordado. Em relação se estes sentiram dificuldades com os conteúdos apresentados, somente $11 \%$ afirmaram que sim e o restante se posicionou de forma negativa.

No último grupo de questões buscamos conhecer os resultados de uma das ações do programa e-TEIA, que foram as palestras. Questionamos os professores/ouvintes se eles se sentiam mais seguros em utilizar os recursos tecnológicos apresentados durante as palestras e, das respostas, $92 \%$ afirmaram de forma positiva e apenas $8 \%$ ainda apresentaram dúvidas e insegurança. Questionamos ainda, se utilizariam algum dos recursos apresentados durante a(s) palestra(s) e quais. Destes, 65,5\% afirmaram que utilizariam sem problemas, $27,4 \%$ utilizariam às vezes (dúvidas) e apenas 7,1\% não utilizariam. Dos recursos apresentados, a maioria apontou o uso de Games educacionais, apesar das redes sociais serem recursos muito conhecidos e corriqueiros entre os alunos da escola.

\section{Considerações Finais}

A pesquisa realizada pelos alunos bolsistas através do programa e-TEIA, focando o uso das TDIC na sala de aula, é um exemplo de interlocução da UFJF com a comunidade, principalmente com os professores da rede pública de ensino, pois ao mesmo tempo que os alunos bolsistas aprendem, estão ensinando, ou seja, repassando o conhecimento construído durante as disciplinas do curso de graduação em Licenciatura em Computação.

Com relação à pesquisa apresentada, concluímos que a utilização das TDIC na sala de aula das escolas pesquisadas ainda é precária. Isso foi possível observar em quase todas as respostas analisadas, desde o baixo percentual de professores que fizeram algum tipo de cursos específicos para o uso das TDIC, até a não utilização dos laboratórios de informática, bem como das dificuldades apresentadas por eles quando questionados sobre os motivos da não utilização das TDIC no processo de ensino e aprendizagem. Porém, ao mesmo tempo que os professores afirmam não utilizarem as TDIC na sala de aula, seja por quaisquer dos motivos elencados, os mesmos tem consciência de que as tecnologias facilitam e auxiliam no processo educacional e que, é necessário uma formação continuada.

Ao finalizar a pesquisa, os professores declaram estar mais seguros quanto a utilização das TDIC e isso, confirma algumas de nossas convicções quanto à necessidade de capacitação e atualização de conhecimentos de forma continuada durante a vida profissional dos professores.

O programa de extensão e-TEIA já inicia neste ano, sua segunda edição e, com desafios ainda maiores, desenvolver oficinas práticas nas escolas, buscando envolver ainda mais os professores e gestores das escolas.

\section{Referências}

Brasil. Decreto $\mathrm{n}^{\mathrm{o}}$ 5.622. 2005. Disponível em: <http://www.planalto.gov.br/ccivil_03/__ato20042006/2005/Decreto/D5622.htm>. Acesso em: 05 mai. 2017.

Cetic. Pesquisa sobre o uso das tecnologias da informação e comunicação nas escolas brasileiras [livro eletrônico] TIC educação 2014. São Paulo : Comitê Gestor da Internet no Brasil, 2015.

Demo, P. Questões para Teleducação. Petrópolis, RJ: Vozes, 1998.

Demo, P. Educação hoje: "novas" tecnologias, pressões e oportunidades. São Paulo: Atlas, 2009.

Kenski, V. M. O ensino e os recursos didáticos em uma sociedade cheia de tecnologias. In: VEIGA, I. P. A. (org). Repensando a Didática. Campinas/SP: Papirus, 2008.

Liguori, L. M. As novas tecnologias da informação e da comunicação no campo dos velhos problemas e desafios educacionais. In: LITWIN, Edith. (Org.)Tecnologia Educacional: política, história e propostas. Trad. Ernani Rosa Porto Alegre: Artes Médicas, 1997.

Masetto, M. T. Mediação pedagógica e o uso da tecnologia. In: Moran, José Manuel (org.). Novas tecnologias e mediação pedagógica. Campinas, SP: Papirus, 2000. 
Moran, J. M. Mudanças na comunicação pessoal: gerenciamento integrado de comunicação pessoal, social e tecnológica. São Paulo: Paulinas, 1998.

Moran, J. M. et al. Novas tecnologias e mediação pedagógica. 6. ed. Campinas: Papirus, 2000.

PeterS, O. A educação a distância em transição. Tradução Leila F. de Souza Mendes. Porto Alegre: UNISINOS. 2003.

Scheidemantel. S. E.; Klein. R.; Teixeira. L. I. A Importância da Extensão Universitária: o Projeto Construir. Anais do $2^{\circ}$ Congresso Brasileiro de Extensão Universitária
Belo Horizonte - 12 a 15 de setembro de 2004. Disponível em: $<$ https://www.ufmg.br/congrext/Direitos/Direitos5.p df $>$. Acesso em: 09 jun. 2017.

Scortegagna, L. Informática na educação. Juiz de Fora, MG. Editora Cead. 2014.

Valente, J. A. Por que o computador na educação? In: Computadores e conhecimento: repensando a educação. Campinas: Gráfica Central da UNICAMP, $1993 . \quad$ p. 24-44. 